\title{
A IMPORTÂNCIA DO PROCESSO DE INICIAÇÃO DO CICLO DE VIDA DO PROJETO NA GESTÃO DA INOVAÇÃO NA CONSTRUÇÃO CIVIL
}

\begin{abstract}
Álisson de Oliveira ${ }^{1}$
RESUMO: O cenário da construção civil apresenta muitos retrabalhos e uma busca constante por qualidade na entrega dos produtos. Apesar de diversas metodologias de gerenciamento de projetos já terem sido inseridas em muitos canteiros de obras, o descuido na fase inicial do projeto, principalmente na definição de todas as pessoas interessadas, comprometerá de forma considerável em vários aspectos a entrega do produto. Com o intuito de apresentar sugestões e caminhos para boas práticas e de se evitar possíveis adversidades, foi realizada uma pesquisa bibliográfica de cunho exploratório em artigos de relevância neste contexto através de pesquisa no portal de Periódicos da Capes. Em decorrência, podemos observar a importância e influência que um processo de iniciação em gerenciamento de projetos bem organizado e executado tem para o resultado final do produto a ser entregue.
\end{abstract}

Palavras-chave: Gerenciamento de projetos. Inovação. Tecnologia. Construção civil.

ABSTRACT: The civil construction scenario presents many reworks and a constant search for quality in the delivery of products. Although several project management methodologies have already been introduced in many construction sites, carelessness in the initial phase of the project, especially in defining all interested people, will considerably compromise the delivery of the product in several aspects. In order to present suggestions and paths for good practices and to avoid possible adversities, a bibliographic research of an exploratory nature was carried out on relevant articles in this context through a search on the Capes Periodicals portal. As a result, we can observe the importance and influence that a well-organized and executed initiation process in project management has for the final result of the product to be delivered.

Keywords: Project management. Innovation. Technology. Civil construction.

\section{INTRODUÇÃO}

A indústria da construção civil no Brasil exerce de forma sistemática um alto impacto não somente na economia, mas também na sociedade. Neste cenário, mesmo representando um número expressivo do PIB brasileiro de acordo com o Departamento Intersindical de Estatística e Estudos Socioeconômicos, DIEESE (2019), muitos dos

\footnotetext{
' Master in Business Administration - Gestão Ágil - (PÍTAGORAS - UNOPAR). Especialista em Gerenciamento de Projetos - Fundação Getúlio Vargas - (FGV). Especialista em Cidades Inteligentes Tecnologia e Inovação (PÍTAGORAS - UNOPAR). Especialista Gerenciamento da Construção Civil com Enfoque na Metodologia BIM. (ESBon). Graduação em Engenharia Civil - Pontifícia Universidade Católica de Minas Gerais. E-mail: alissonbeaga@hotmail.com
} 
processos construtivos permanecem o mesmo por décadas, e no que tange a inovação, a indústria de Arquitetura, Engenharia e Construção (AEC) carece de muitas transformações não apenas no âmbito da gestão, mas também no aspecto cultural, já que em empreendimentos de pequeno e médio porte, o processo construtivo ainda é um fator de certa relevância no momento da aquisição.

As empresas de construção ainda apresentam baixa produtividade, sobretudo devido ao seu baixo nível de industrialização. Fatores como a limitada qualificação de profissionais e o elevado desperdício de materiais contribuem para resultados insatisfatórios na qualidade do produto final. Muitos empreendedores do setor estão empenhados em buscar métodos considerados mais ágeis para desenvolver uma melhor gestão do escopo do projeto com o propósito de uma entrega mais rápida do produto e claro, com um alto valor agregado, consequentemente, uma melhoria nos aspectos inerentes ao ciclo de vida do produto.

Diversas metodologias de gestão de projetos vêm sendo aplicadas nas fases iniciais do projeto, fase que é considerada como a que possui os melhores predicados para a viabilização de novos conceitos de forma a propiciar resultados melhores no que se refere tanto a questões econômicas e ambientais. Reduzir desperdícios, minimizar riscos, aumentar a produtividade, além de estabelecer ações que visam aumentar a eficiência do processo construtivo, constituem o cerne da gestão de projetos. Segundo Vargas (2009), todo o sucesso de uma gestão de projetos está em identificar e relacionar as atividades a serem desenvolvidas no momento correto.

Mesmo com todo esse arcabouço, na fase de iniciação do projeto, onde acontece os primeiros encontros e reuniões entre os stackholders, expressão da língua inglesa para pessoas interessadas seundo Kretan et al (2009), na maioria das vezes muitas decisões e informações são deixadas de lado e afetam sistematicamente no modo de condução do projeto. A ansiedade de começar a materializar logo as edificações, faz com que se pule etapas importantes e certamente no final será necessário voltar e efetivar o que foi menosprezado.

Portanto, no contexto apresentado, o objetivo fundamental deste trabalho, é o de apresentar a importância do processo de iniciação do ciclo de vida de um projeto na concepção de inovações tecnológicas em projetos de Arquitetura e Engenharia Civil, contextualizando a metodologia preditiva do Project Management Institute (PMI). 
A metodologia empregada para o desenvolvimento deste artigo foi a de pesquisa bibliográfica exploratória. Sendo investigado pelo autor publicações categorizadas no âmbito da relevância no portal de periódicos da Capes e não por uma grande quantidade de artigos acadêmicos. Assim sendo, o intuito não deixa de escapar a uma bibliografia que consiga de modo lacônico representar o estado da arte, e destacar-se pela, abrangência e significância.

\section{FUNDAMENTAÇÃO TEÓRICA}

De acordo com o $P M B o K^{\circledR}$ (PMI, 2017), um projeto é um esforço temporário empreendido para criar um produto, serviço ou resultado exclusivo. E essa atividade temporária com objetivo único, tem o intuito de resolver um problema e ou aproveitar uma oportunidade, sempre com uma avaliação das necessidades.

Um projeto refere-se a um empreendimento com proposito muito bem estabelecido, que irá consumir recursos das mais variadas espécies e fundamentados pela restrição de escopo, tempo e custos. Os projetos são oriundos de um vínculo direto entre as expectativas de cliente com o resultado final gerando uma demanda (HELDMAN, 2009). Se faz necessário uma comunicação bem ampla e com um alto teor de informações disponibilizadas para que todas as partes interessadas fiquem cientes de toda expectativa que o projeto trará.

A contribuição de todos os envolvidos no projeto é crucial para o bom andamento e sucesso. Os fatores determinantes para que se chegue ao sucesso em um projeto, podem ser compreendidos como um grupamento de características, circunstâncias ou variáveis que repercutem de forma significativa sobre o sucesso ou fracasso de um projeto (VALLE et al, 2014).

O gerenciamento de projetos abarca inúmeras técnicas, ferramentas e metodologias para identificar, planejar, monitorar e controlar toda a jornada das atribuições préestabelecidas para se chegar à entrega do produto ou serviço. Como todo cenário de projetos é suscetível a inúmeras mudanças, as ferramentas utilizadas podem ser distribuídas e segmentadas em fases. Segundo Vargas (2009), a compreensão e domínio das fases do projeto, permite a todos os envolvidos um melhor controle de recursos e gastos para se alcançar os objetivos definidos. 
Existem processos de gerenciamentos que irão nortear o caminho, e auxiliar no controle, já que em um projeto poderá existir um número muito grande de atividades a desenvolver. Mesmo dentro de um projeto existem ciclos que começam e terminam, dessa forma, a divisão do projeto para auxiliar a progressão de acordo com cada item que é executado e finalizado é sempre recomenda.

Essa divisão do projeto em cinco fases, é definida pelo $P M B o K^{\circledR}$ (PMI, 2017), como ciclo de vida do projeto, e pode ser estabelecida em um agrupamento de fases comuns a todas as vertentes de projetos, compreendendo um encadeamento de ações para que se atenda em sua totalidade uma determinada demanda do projeto. De acordo com Vargas (2009), cada fase do projeto, é determinada pela entrega, ou finalização de um determinado trabalho.

Os processos de gerenciamento definidos correspondem as etapas de: iniciação (onde determinadas necessidades são apontadas para que se defina um novo projeto ou uma nova fase); planejamento (etapa em que será detalhado todas as atividades que serão realizadas no projeto e definição de todas as estratégias); execução (fase de execução das trabalhos estabelecidos nas etapas anteriores); monitoramento e controle (acompanhar e analisar o status atual do projeto com o que foi previsto, realizando as ações necessárias quando acontecer desvios do planejamento); encerramento (conclusão das atividades dos demais grupos e avaliação de erros e acertos durante o projeto).

Conforme Rocha (2013), os processos de cada grupo de processos do ciclo de vida, são executados paralelamente ao longo do tempo dentro das fases e sempre variando de acordo com a intensidade de sua execução, verificando a interação entre eles como mostra a Figura I.

Figura I - Sobreposição dos grupos de processo em um projeto

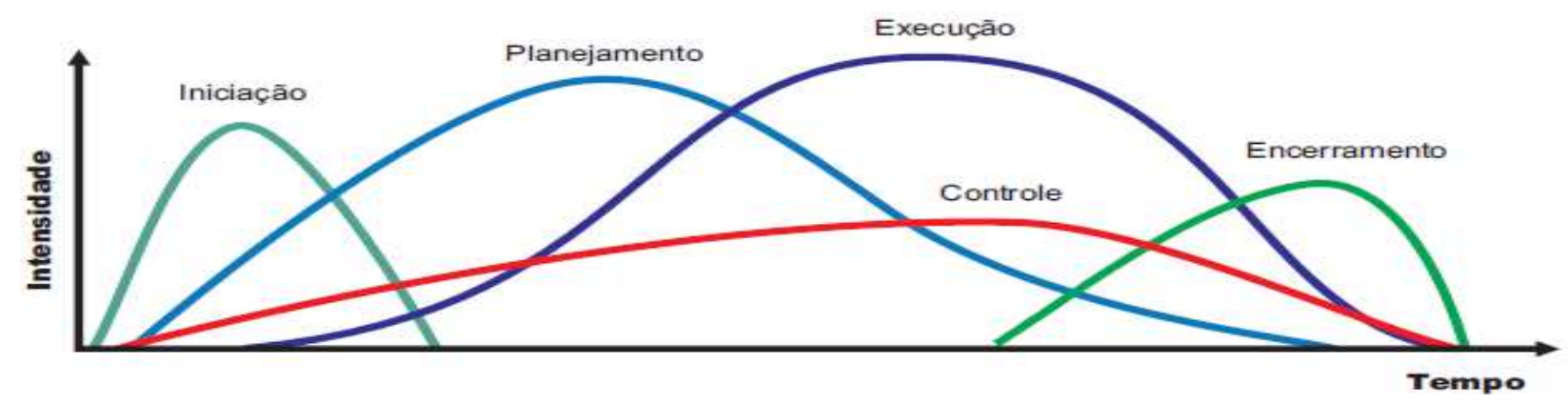

Fonte: https://felipelirarocha.wordpress.com/2013/o7/13/ciclo-de-vida-de-projeto/ (acesso em 04/or/2022). 
Os grupos de processos de gerenciamento de projetos direcionam de forma eficaz e controlada o projeto em direção as suas entregas finais, ou seja, a sua conclusão. Como aponta Valle et al (2014), os grupos de processos se relacionam em função de sua categoria, objetivos e efeitos, podendo de ser verificados como atividades que se superpõem com maior ou menor intensidade durante o projeto ou fases.

O início de cada projeto reflete uma fase preliminar de melhor reconhecimento das necessidades e onde essas demandas podem ser melhor analisadas para que se estruture o melhor rumo a se tomar. Vargas (2009), define que quando a maioria dos anseios ainda está no papel, é o melhor momento de adicionar valor ao projeto e o custo de implementar novas concepções e mudanças ainda é relativamente pequeno.

É na etapa de iniciação que serão definidos a missão e objetivos do projeto de modo mais abrangente, é a chamada fase de conceituação pois quando a necessidade é identificada e convertida em um problema estruturado, será considerado como início do projeto.

Formalmente a fase de iniciação contempla o desenvolvimento do termo de abertura do projeto, que segundo Montes (2017), é o documento que sanciona formalmente o início do projeto, que além de nomear, irá credenciar autoridade ao gerente de projetos para empregar os recursos e ferramentas organizacionais nas atividades do projeto.

O termo de abertura do projeto concentra diversas informações extremamente importantes e pertinentes ao projeto dentre elas a justificativa, objetivos, metas, premissas, restrições além de custos e prazos estimados, são os principais aspectos contidos em quaisquer termos de abertura. Essas informações darão subsídios para que se tenha em mente a continuidade ou não de cada projeto.

A viabilidade de cada projeto é analisada por todos os stakeholders com uma análise bem detalhada do termo de abertura de projeto. Com as informações coletadas pode se estudar os riscos e conceber de forma racional as melhores estratégias para atender em sua totalidade as necessidades do projeto.

Outro fluxo de processo formal a fase de iniciação é a de identificar as partes interessadas do projeto. Com todos os dados coletados para o termo de abertura do projeto se faz necessário identificar, juntamente com seus interesses, envolvimentos e impacto no sucesso do projeto. Segundo o $\mathrm{PMBoK}^{\circledR}$ (PMI, 2017), a vantagem principal deste processo 
é a de outorgar a equipe do projeto uma identificação do direcionamento adequado para engajar cada parte interessada ou grupo de partes interessadas.

Este processo é realizado de forma regular ao longo de todo o projeto, conforme cada necessidade que porventura surja. Por este motivo, Montes (2017), expõe que talvez este seja o processo mais crítico do gerenciamento de projetos, visto que descobrir todas as partes interessadas e escuta-las de modo eficaz no início, irá trazer um grande comprometimento, maior compreensão dos requisitos e objetivos, resultando em menos alterações em todo transcorrer do projeto.

Uma especificação mal sucedida de todas as partes significativas ao projeto, de forma a não elencar todos, poderá trazer várias solicitações de modificações no escopo, criando situações de difíceis articulações para o gerente de projeto, além de gerar objeção de partes que não foram incluídas. Um fator análogo é que estratégias e atividades podem ficar de fora do que foi definido, ocasionado em perdas significativas ao bom andamento do projeto, já que a coleta de informações no início é amplamente discutida através de práticas onde todos participam, como por exemplo a do brainstorming, que em sua tradução literal significa tempestade de ideias.

\section{PRÁTICAS DA GESTÃO}

O âmbito mais favorável para qualquer implementação de atividade ou metodologia é sempre aquele onde ainda não houve gastos consideráveis, seja de qualquer natureza. Da mesma maneira este é o cenário ideal para tencionar a aplicação de soluções inovadoras.

Segundo Rodríguez (2017), o desenvolvimento e a efetivação de tecnologias necessitam de prudência não somente dos avanços tecnológicos e da engenharia, mas de forma similar dos recursos humanos, das matérias primas, das modalidades de financiamento e do cenário em que essas tecnologias serão inseridas.

Não se pode pensar na inserção das inovações e tecnologias de forma arbitrária, sem o devido planejamento, é imprescindível a gestão dessas inovações com o extremo rigor. A gestão da inovação ou gestão tecnológica, desponta como uma resposta para este aspecto, onde a utilização da inovação e tecnologia aliadas a ciência supre as demandas relacionadas as condições estratégicas das empresas das mais variadas vertentes, e claro, do ramo da construção civil. 
Contudo, de acordo com Reichstein; Saltes; Gann (apud Granja, 2015), na construção civil as principais mudanças tecnológicas se delimitam entre a inserção de novos sistemas processos construtivos e componentes de construção. Mesmo sendo realizadas de forma constante inúmeras adequações no que tange a conceitos de qualidade, desempenho e sustentabilidade ambiental.

Não obstante de todos os empenhos e do êxito quanto a adoção de novas tecnologias no desenvolvimento de projetos, ainda são encontradas inúmeras dificuldades para que essas inovações cheguem aos canteiros de obras, raramente extrapolando as salas dos escritórios, de acordo com Regina de Freitas (2015).

Deve-se compreender o cenário em que se encontra o projeto e ter um amplo debate e estudo para se definir todas as partes interessadas que sejam especialistas nos mais variados aspectos e que possam contribuir de forma eficaz para a introdução de tecnologias. Tanto em uma pequena construtora, quanto em um projeto de uma residência unifamiliar, a investigação de práticas já bem estabelecidas em outros projetos podem determinar novos rumos ao empreendimento e evitar desde retrabalhos esporádicos até a maximização do lucro esperado.

Em uma indústria em que se apresentam colaboradores das mais diferentes importâncias e magnitudes, a construção civil agrega valor desde a concepção de um projeto. O gestor de projeto deve ter habilidades interpessoais, técnicas e administrativas para aglutinar e agrupar pessoas que possam propor conceitos que levem a melhorias no desenvolvimento do projeto ou até mesmo a novas possibilidades nunca empregadas.

Barassa (2017), aponta que a invenção é determinada pela criação de algo com uma nova aplicação que tem por propósito a resolução de algum contratempo prático ou inclusive uma finalidade completamente nova.

Com a definição dos stakeholders, o gestor expõe as perspectivas de projeto e pode estipular áreas que são favoráveis. Um caminho a seguir é a utilização de um modelo de radar de inovação, esta ferramenta amplifica a percepção de inovação incorporada pelos stakeholders e é aplicada para mensurar o grau de inovação em empreendimentos baseada em análise de dados e acontecimentos, como apresentada na Figura 2. 
Figura 2-Radar de inovação

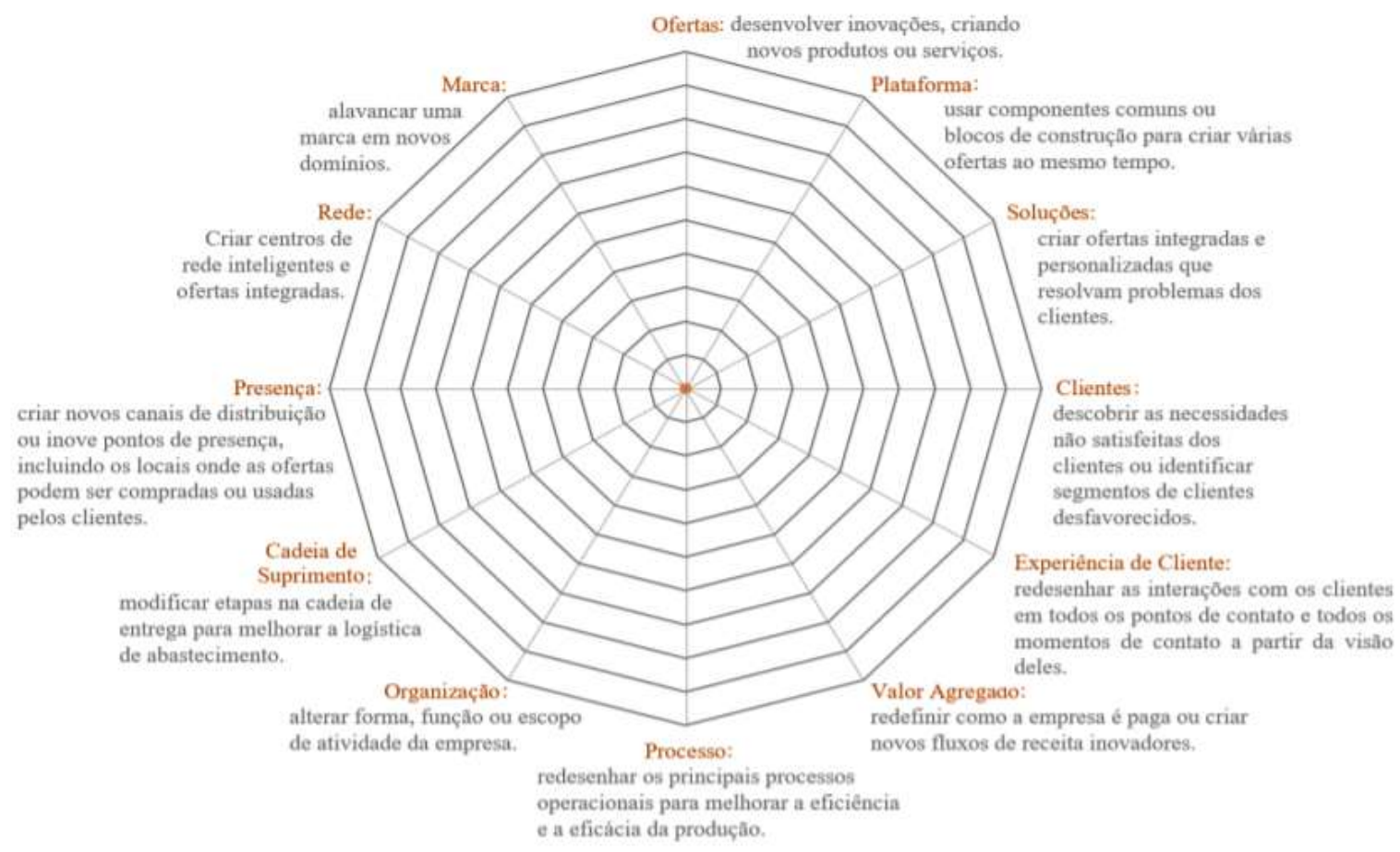

Fonte: Beserra et al (2020).

A ferramenta apresentada remete ao estudo em doze áreas (ofertas, plataforma, soluções, clientes, experiência de cliente, valor agregado, processo, organização, cadeia de suprimentos, presença, rede e marca), assim são comparados entre períodos ou diferentes empresas e quais foram os avanços e melhorias apresentadas por todas elas.

Segundo Kerzner (20II), devido as complexidades dos projetos e a velocidade em que acontecem as mudanças tecnológicas, a expectativa é que os gerentes de projetos comprovem mais habilidades no entendimento das tecnologias do que um comando sobre elas.

O fluxo de trabalhado fundamentado pela metodologia preditiva do Project Management Institute é capaz de fornecer resultados bastante positivos se bem estruturado. Dificuldades como preconceito, temor a metodologia, burocracia e quantidade de informações documentadas são os primeiros fatores que deverão ser superados.

Segundo Schreiber (2016), nem sempre se faz necessário o emprego de uma inovação considerada radical de produtos, serviços ou sistemas para proporcionar condições favoráveis a construção de um diferencial. Entre todas as ferramentas disponíveis é preciso 
adequar todas as mudanças de acordo como perfil de cada projeto e partes interessadas para que não ocorram choques de ideias e as mudanças deixem de seguir o fluxo necessário.

\section{CONSIDERAÇÕES FINAIS}

O Cenário da construção civil ao longo do tempo não foi muito alterado quando se fala de técnicas construtivas ou materiais utilizados, nunca estando na vanguarda como outras indústrias ou setores econômicos. A enorme quantidade de retrabalho ainda é algo que se deve combater em muitos canteiros de obras, principalmente naqueles que apresentam uma falta de organização gerencial e também onde existe o receio de incorporar novos meios de se chegar à entrega dos produtos.

Apenas efetivar esta entrega do que foi acordado no início, hoje já não basta, pois os inúmeros obstáculos que permeiam os meandros da construção civil irão afetar e muito a qualidade do produto final. E será preciso muitos outros preceitos além dos gastos que não contemplam nos orçamentos, para se contornar estas adversidades.

Práticas como uma eficaz definição das pessoas interessadas que é um dos processos de iniciação do ciclo de vida do projeto, podem trazer melhorias significativas ao setor da construção, eliminando baixa produtividade aprimorando a qualidade das entregas gerando competitividade e desenvolvendo o setor como um todo. Eliminando muitos problemas até mesmo antes de uma possível ocorrência.

O sucesso de projetos realizados com um grande empenho na fase de início está profundamente vinculado a uma disseminação e conscientização de todas as benesses que todas as partes interessadas irão alcançar.

O investimento constante em treinamentos e atualização contínua de todos os stakeholders do projeto, fornecerá subsídios para que a inovação encontre portas abertas para se proliferar e conceber um avanço perceptível em toda a cadeia da indústria da construção civil.

\section{REFERÊNCIAS BIBLIOGRÁFICAS}

BARASSA, Edgar. Tendências e Inovação. Valinhos, 2017.

DIEESE, Departamento Intersindical de Estatística e Estudos Socioeconômicos. A Construção Civil e os Trabalhadores: panorama dos anos recentes. São Paulo, 2020. 
GRANJA, Ariovaldo Denis. Inovação tecnológica na construção civil. PARC Pesquisa em Arquitetura e Construção, Campinas, SP, v. 6, n. 4, p. 252- 254, dez. 2015.

HELDMAN, K. Gerência de Projetos. 5.ed. Tradução: Edson Furmankiewicz. Rio de Janeiro: Elsevier. 2009.

KERZNER, Harold. O Que os Executivos Precisam Saber Sobre Gerenciamento de Projetos. Ed.Bookman, 20II.

Kretan, A. et al. Gerenciamento de stakeholders: um fator crítico para o sucesso em projetos. Revista Mundo Project Management, 4(24), 62. 2009.

MONTES, Eduardo. Introdução ao Gerenciamento de Projetos: Como gerenciar projetos pode fazer a diferença na sua vida, ${ }^{-}$Ed. São Paulo; 2017.

PMI. Um guia do conhecimento em gerenciamento de projetos. Guia PMBOK ${ }^{\circledR}$ 6a. ed. - EUA:Project Management Institute, 2017.

REGINA DE FREITAS, M. O canteiro de obras brasileiro em termos da adoção de recursos tecnológicos - em busca de melhoria das práticas através da inovação dos processos. reec - revista eletrônica de engenharia civil, [s. 1.], v. Io, n. I, 2015. https://www.revistas.ufg.br/reec/article/view/31422. Acesso em: 9 jan. 2022.

ROCHA, Felipe. Ciclo de Vida de um Projeto. Disponível em: $\langle$ https://felipelirarocha.wordpress.com/2013/o7/13/ciclo-de-vida-de-projeto/.〉. Acesso em 04 de jan. de 2022.

RODRÍGUEZ, Lady Tatiana Bermúdez. Gestão da Inovação. Valinhos: 2017.

SCHREIBER, D.; PINHEIRO, I. A. analysis of the innovative practices at construction industry (análise das práticas de inovação em construção civil). contextus - revista contemporânea de economia e gestão, v. I4, n. 2, p. 6-35, 26 out. 2016. 
VAllE, André B. et al; Fundamentos do Gerenciamento de Projetos. Série Gerenciamentos de Projetos. 3. Ed. São Paulo: FGV, 2014.

VARGAS, Ricardo V. Gerenciamento de Projetos: Estabelecendo Diferenciais

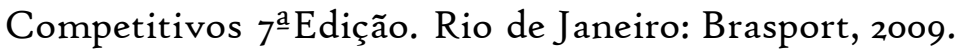

SILVA, W. A. da .; FONSECA, G. F. .; SILVEIRA, W. F. . BIM: The technological challenges and professional innovation of civil engineering in the state of Maranhão. Research, Society and Development, [S. 1.], v. Io, n. 17, p. eig6101724530, 2021. 